\title{
Event-related potential and behavioural differences in affective self-referential processing in long-term meditators versus controls
}

\author{
Sucharit Katyal ${ }^{1,2}$ (D) $\cdot$ Greg Hajcak $^{3} \cdot$ Tamara Flora $^{1} \cdot$ Austin Bartlett $^{1} \cdot$ Philippe Goldin $^{1}$
}

Published online: 24 January 2020

(C) The Psychonomic Society, Inc. 2020

\begin{abstract}
Contemplative practices are thought to modify one's experience of self and fundamentally change self-referential processing. However, few studies have examined the brain correlates of self-referential processing in long-term meditators. Here, we used the self-referential encoding task (SRET) to examine event-related potentials (ERP) during assessment of pleasant and unpleasant self-views in long-term meditators versus age-matched meditation-naïve control participants. Compared with controls, meditators endorsed significantly more pleasant and fewer unpleasant words as self-referential. We also found a between-group difference in the early component of the late-positive-potential (LPP) of the ERP characterized by a larger response to unpleasant versus pleasant words in controls and no difference in meditators. A cross-sectional design, such as the one used in the present study, has certain caveats like self-selectivity bias. If such caveats did not affect our results, these findings suggest that a long-term contemplative lifestyle, of which meditation training is an integral part, alters self-referential processing towards a more adaptive view of self and neural equivalence towards pleasant and unpleasant self-views. These findings suggest that long-term meditation training may affect brain and behavioural mechanism that support a more flexible and healthy relationship to one's self.
\end{abstract}

Keywords Self-reference $\cdot$ Emotion $\cdot$ Meditation $\cdot$ SRET $\cdot$ EEG $\cdot$ ERP $\cdot$ Late-positive potential

A majority of studies on meditation training have focused on how it affects cognitive faculties such as attention, executive functioning, and emotional regulation (for review, see Chiesa, Calati, \& Serretti, 2011; Tang, Hölzel, \& Posner, 2015). Contemplative literature, both from traditional and contemporary perspectives, highlights another psychological process that is critical to mental development and well-being - the practitioner's experience and construct of self (e.g., Albahari, 2006; Anandamurti, 1998; Austin, 2011; Dahl, Lutz, \& Davidson, 2015; E. Thompson, 2014; Vago \& Silbersweig, 2012). Meditation training is also thought to

Electronic supplementary material The online version of this article (https://doi.org/10.3758/s13415-020-00771-y) contains supplementary material, which is available to authorized users.

Sucharit Katyal

sucharit.katyal@gmail.com

1 University of California Davis, Davis, CA, USA

2 Danish Technical University, Building 321, DTU, 2800 Kongens Lyngby, Denmark

3 Department of Biomedical Sciences and Psychology, Florida State University, Tallahassee, FL, USA enhance an equanimous disposition in response to affectively charged situations (Desbordes et al., 2015). Few neuroscientific studies have, however, explicitly examined how views of self and self-related processing changes with long-term meditation training. In this study, we investigate, for the first time, the effect of long-term meditation training on behavioural and ERP indicators of self-referential processing.

\section{Self-referential processing}

Humans process information pertaining to themselves preferentially and more deeply compared with information not pertaining to themselves (e.g., Rogers, Kuiper, \& Kirker, 1977; Symons \& Johnson, 1997). While such preferential processing would have been an evolutionarily adaptive trait for self-preservation, excessive self-focused rumination has been shown to be maladaptive for mental health (e.g., Mellings \& Alden, 2000; Watkins \& Teasdale, 2001). Thus, developing facility and flexibility in relating to one's self may be a fundamental facet of sustained well-being.

A widely studied behavioural paradigm that demonstrates preference for self-processing is the self-referential encoding task (SRET; Rogers et al., 1977). In the classic version of 
SRET, individuals are presented a series of words under a selfreferential (e.g., judging if words are self-descriptive) and a non-self-referential (e.g., semantic judgement) condition, and are subsequently able to better recall self-referential words (e.g., Symons \& Johnson, 1997). Preferential self-referential processing is further amplified when affective, rather than neutral, words are involved (e.g., Fields \& Kuperberg, 2012; Fossati et al., 2003; Herbert, Pauli, \& Herbert, 2011b). The affective version of the SRET that uses both pleasant and unpleasant words has also been used to differentiate healthy from clinical populations. While healthy individuals selfendorse and subsequently recall more pleasant compared with unpleasant words, depressed and anxious populations show the opposite pattern (Derry \& Kuiper, 1981; Dozois \& Dobson, 2001; Kuiper \& Derry, 1982; Lemogne et al., 2010; Rogers et al., 1977; Shestyuk \& Deldin, 2010).

\section{Neural correlates of self-referential processing}

The human brain has a dedicated network of regions for the preferential processing of self-related information, most prominently the medial frontal-parietal brain network (Knyazev, 2013; Fossati et al., 2003; Gusnard, Akbudak, Shulman, \& Raichle, 2001; Northoff \& Bermpohl, 2004; Ochsner et al., 2004). Self-related emotional information additionally recruits other regions, including the insula and amygdala, as assessed by fMRI (Banks, Eddy, Angstadt, Nathan, \& Phan, 2007; Ochsner et al., 2004; Yoshimura et al., 2009). Neural correlates of affective self-referential processing have also been investigated using event-related potentials (ERPs; Auerbach, Stanton, Proudfit, \& Pizzagalli, 2015; Herbert, Herbert, Ethofer, \& Pauli, 2011a; Herbert, Pauli, et al., 2011b; Holt, Lynn, \& Kuperberg, 2009; Shestyuk \& Deldin, 2010; Watson, Dritschel, Obonsawin, \& Jentzsch, 2007). These ERP studies have repeatedly observed differences in the P200 and the latepositive-potential (LPP). The P200 is an ERP component observed around $200 \mathrm{~ms}$ after stimulus onset over the medialcentral electrode sites, and is thought to reflect automatic semantic processing or attentional capture by emotional stimuli (Crowley \& Colrain, 2004; Huang \& Luo, 2006; Thomas, Johnstone, \& Gonsalvez, 2007). The LPP is a more sustained slow wave component of the ERP starting approximately $350 \mathrm{~ms}$ following stimulus onset and is related to sustained attentional and emotional engagement with stimulus content (Dennis \& Hajcak, 2009; Hajcak, Dunning, \& Foti, 2009; Naumann, Bartussek, Diedrich, \& Laufer, 1992; Ruchkin, Johnson, Mahaffey, \& Sutton, 1988; Schupp et al., 2000). Thus, these two components are distinct ERP components that might be modified by long-term training in methods that influence attention regulation.
Both P200 and LPP amplitudes have been found to increase for affective compared with neutral stimuli (Fischler \& Bradley, 2006; Foti, Hajcak, \& Dien, 2009; Hajcak \& Olvet, 2008; Herbert, Junghofer, \& Kissler, 2008; Kissler, Herbert, Peyk, \& Junghofer, 2007). This difference is also observed when comparing valence of affective selfreferential stimuli. However, the findings are mixed. The P200 and LPP amplitudes have been found to be both greater for pleasant compared with unpleasant self-referential words (Auerbach et al., 2015; Herbert, Herbert, et al., 2011a; Shestyuk \& Deldin, 2010; Watson et al., 2007) as well as greater for unpleasant compared with pleasant ones (Fields \& Kuperberg, 2012; Herbert, Pauli, et al., 2011b; Zhou et al., 2017) in separate studies. ERP differences between pleasant and unpleasant words in the SRET have been used to identify brain patterns that differentiate healthy and clinical populations. Studies have shown that, compared with healthy control groups, individuals who are clinically diagnosed with or who are prone to depression and borderline personality disorder show a much greater difference in ERP responses between unpleasant and pleasant words for the P200 (Auerbach et al., 2016; Shestyuk \& Deldin, 2010), a slightly earlier P100 (Auerbach et al., 2015), and the LPP (Auerbach et al., 2015; Auerbach et al., 2016; Shestyuk \& Deldin, 2010; Speed, Nelson, Auerbach, Klein, \& Hajcak, 2016) components.

The LPP has been subdivided into early $(\sim 300-600 \mathrm{~ms}$ following stimulus onset) and late (>600 ms following stimulus onset) components (Auerbach et al., 2016; Dennis \& Hajcak, 2009; Foti et al., 2009). Functionally, the early-LPP is implicated in affective encoding, attention, and arousal (Naumann et al., 1992; Paulmann, Bleichner, \& Kotz, 2013; Schupp et al., 2000), whereas late-LPP is thought to reflect mnemonic aspects of affective processing and prolonged effortful processing (Ruchkin et al., 1988). For affective SRET specifically, group differences between healthy and clinical samples in response to pleasant and unpleasant adjectives have been observed in the early-LPP (Shestyuk \& Deldin, 2010), late-LPP (Auerbach et al., 2016), or both early-LPP and late-LPP components (Auerbach et al., 2015).

\section{Contemplative training and self-referential processing}

There are different types of contemplative disciplines and practices. A common theme across them is that meditation training transforms the practitioner's experience and understanding of self (e.g., Anandamurti, 1998; Dorjee, 2016; Sedlmeier \& Srinivas, 2016; Vago \& Silbersweig, 2012). As meditation practitioners become more adept with the practice of calming the mind, they gain the capacity to "de-reify" or "de-fuse" from the contents of one's mind (e.g., Bishop et al., 
2004; Lutz, Jha, Dunne, \& Saron, 2015). Through such cognitive defusion, practitioners are thought to differentiate themselves from contents of their mind, almost as if being able to experience mental phenomena as a "movie" of transient events (Sedlmeier, 2018). Based on this idea, when a selfreferential stimulus is presented, an expert meditator would recognize the stimulus as a mere transient mental object. In contrast, a meditation-naïve person might engage in prolonged self-referential rumination. Consistent with this idea, long-term meditators show reduced brain activity in midline cortical areas (i.e., medial prefrontal cortex, medial parietal cortex) associated with self-referential processing (Berkovich-Ohana, Glicksohn, \& Goldstein, 2012). Shortterm mindfulness meditation training, such as an 8-week mindfulness-based stress reduction (MBSR) course, has also been shown to yield reduced activity in cortical midline regions (Berkovich-Ohana et al., 2012; Farb et al., 2007). Moreover, in an affective context, a de-reified stance towards one's mental contents might enable a meditation practitioner to have a less preferential response towards pleasant and unpleasant valence compared with a meditation-naïve individual (Sobolewski, Holt, Kublik, \& Wróbel, 2011).

Even before a meditator accomplishes the long-term goal of completely de-fusing from one's mental content, a mere reduction in fusion with self-referential content can help reduce unpleasant or negative feelings towards oneself and help foster an attitude of self-acceptance and selfsatisfaction (Jimenez, Niles, \& Park, 2010; Ramesh, Sathian, Sinu, \& Kiranmai, 2013; B. L. Thompson \& Waltz, 2008). For example, one of the 10 ethical components of Yogic contemplative practices, which was the tradition of practices undertaken by our long-term meditation group, is the cultivation of satisfaction or contentment with one's current situation (santosha in Sanskrit; Anandamurti, 1981; Bharati, 2001; Van Ness, 1999). Such a self-satisfied attitude can promote positive mental health and could be one of the ways mindfulness meditation training helps alleviate symptoms of anxiety and depression (Hofmann, Sawyer, Witt, \& Oh, 2010; Jimenez et al., 2010; Kuyken et al., 2015; Segal et al., 2010). An fMRI study examining pre-MBSR versus post-MBSR changes in neural correlates of affective SRET in adults with social anxiety disorder showed decreased endorsement of unpleasant and increased endorsement of pleasant views of oneself accompanied by greater responses in brain regions associated with top-down attention, and reduced activation of the cortical midline (Goldin, Ramel, \& Gross, 2009). However, thus far, no studies have investigated whether much longer term contemplative training is associated with brain and behavioural changes in affective self-referential processing, specifically when targeting three different ERP components (i.e., P200, early-LPP and late-LPP) that might reflect distinct cognitive-affective processes.

\section{The present study}

The goal of this study was to investigate whether, compared with a meditation-naïve control group, long-term meditators are characterized by differences in the P200 and LPP components of the ERP during self-referential processing of pleasant and unpleasant adjectives. To investigate this question, we recorded the EEG while participations performed the SRET in a laboratory setting. We recruited long-term meditators from a Yogic contemplative system where selftransformation is the essential theme of the training (see Method section). We predicted that, compared with the meditation-naïve control group, long-term meditators would show distinct behavioural and brain differences during the SRET. For behavioural responses, based on previous observations of self-views in mentally healthy individuals, we expected that both groups would endorse significantly more pleasant than unpleasant adjectives as self-referential (Derry \& Kuiper, 1981; Dozois \& Dobson, 2001; Kuiper \& Derry, 1982; Lemogne et al., 2010; Rogers et al., 1977; Shestyuk \& Deldin, 2010). Moreover, if long-term meditators have a more self-satisfied and self-accepting outlook, they would endorse significantly more pleasant adjectives (like satisfied, joyful, etc.) and fewer unpleasant adjectives (like sad, depressed, anxious, etc.) as self-referential compared with the control group (Goldin et al., 2009). For ERP responses during the SRET, we expected that (1) long-term meditators would show a larger increase in the difference between pleasant and unpleasant adjectives for the P200, early-LPP, and late-LPP components compared with the control group, paralleling previous comparisons between healthy and depressed/anxious individuals (Auerbach et al., 2015; Auerbach et al., 2016; Shestyuk \& Deldin, 2010; Speed et al., 2016), and/or, (2) long-term meditators would not show a difference in P200, early-LPP, and late-LPP components between pleasant and unpleasant adjectives reflecting a more "neutral" experience of valence, while the control group would (in either direction, as the directionality is unclear from past research). The two statements could also be true simultaneously if the control group showed a larger response to unpleasant compared with pleasant adjectives, with the meditators not showing a difference between the two. Both hypotheses will be tested primarily through a group (meditator, control) by valence (pleasant, unpleasant) interaction in the three ERP components.

\section{Method}

\section{Participants}

Thirteen long-term meditators (four females) from the Ananda Marga community (mean age $=56.8$ years, $S D=12.3$ years) with a mean of 32.2 years of meditation training $(S D=9.7)$, 
and 15 (six females) age-matched controls (mean age $=53.5$ years, $S D=14.2$ years) with no meditation experience participated in the study. Previous ERP studies of affective selfreferential processing have used typical samples sizes of 1525 (e.g., (Herbert, Pauli, et al., 2011b; Shestyuk \& Deldin, 2010)), while ERP studies on long-term meditators have used typical sample sizes of 13-17 (e.g., Cahn, Delorme, \& Polich, 2013; Sobolewski et al., 2011).

The two groups did not differ in years of formal education (meditators: mean $=15.9$ years, $S D=3.0$; controls: mean $=$ 16.4 years, $S D=2.1$; Wilcoxon rank-sum test $=171.5 ; p=.64$, two-tailed). Nine out of 13 individuals from the meditator group were monastics, many of whom reported no direct source of income besides a subsistence support from nonmonastic practitioners. The meditator group (after including the subsistence-level support for monastics) thus had a significantly lower income level in the year prior to the study compared with the controls (Wilcoxon rank-sum test $=69.5 ; p$ $=.011$, two-tailed).

Participants reported no history of psychiatric or neurological disorders. All participants either had English as their first language or were fluent speakers for more than 30 years. All participants provided written informed consent in compliance with the Institutional Review Board at the University of California Davis. All participants reported having normal or corrected-to-normal visual acuity.

Long-term meditators were recruited from the San Francisco Bay Area and national mailing lists of the Ananda Marga (Sanskrit for "Path of Bliss") meditation community. Long-term meditators were included if they had more than 10 years of regular practice of at least 1 hour per day, although most were meditating 2-3 hours daily for the past 10 years. Age-matched meditationnaïve control participants were recruited locally from the Sacramento and Davis areas via online forums and fliers posted in public libraries and at UC Davis. Only two of the control participants had brief experience (less than 2 months in their entire life) with meditation or yoga postures.

Ananda Marga is a Tantric Yogic system originating in India. Practitioners engage in multiple daily practices including moral guidelines (yama and niyama), yogic postures (asanas), controlled breathing (pranayama), focused attention meditation on a phrase (mantra) whose meaning deals with self-transformation, and nondual meditation (dhyana). In the Ananda Marga system, the combination of different practices work synergistically towards the ultimate goal of "self-realization" where one's feeling of an egocentric sense of self is expanded into a transpersonal self-concept, which is in turn merged into a transcendental "Self" beyond mental perturbations (Anandamurti, 1998). In addition to formal sitting meditation, practitioners are highly encouraged to engage in social service to inculcate compassion towards all beings.

\section{Self-referential encoding task}

The SRET was administered via a computer using Presentation ${ }^{\circledR}$ software (Version 18.0, Neurobehavioral Systems, Inc., Berkeley, CA; www.neurobs.com) on a monitor (21-inch diagonal) kept at a distance of $74 \mathrm{~cm}$ from the participant (Auerbach et al., 2015; Speed et al., 2016) . In the SRET, we presented 60 trials with 30 pleasant and 30 unpleasant trait adjectives (see Supplementary Material Fig. S1 for words) taken from the Affective Norms for English Words (ANEW; Bradley \& Lang, 1999). Words were chosen so that they were matched for valence, $t(58)=-0.38, p=.70$, arousal, $t(58)=-1.54, p=.12$, word length, $t(58)=0.70, p=$ .48 , and frequency, $t(58)=1.39, p=.17$. Presentation of words was pseudorandomized. Each trial included a fixation cross presented in the centre of the screen for $500 \mathrm{~ms}$, a single word for $1,000 \mathrm{~ms}$, a fixation cross for $500 \mathrm{~ms}$, and then a question, "Does this word describe you?" Participants were required to respond to this question by pressing the left or right mouse buttons for Yes and No, respectively. A response was mandatory before the next trial could begin. The response was followed by the fixation cross, which remained on the screen for $500 \mathrm{~ms}$ before the appearance of the next word. Words were presented in white on a black background. Height of the words was $5 \mathrm{~cm}$. Prior to beginning the experiment, participants underwent three practice trials using affectively neutral words to familiarize themselves with the task procedures. We confirmed that participants understood the task instructions before starting the SRET. If the task was not clear to the participants following the three practice trials, we described the task again and redid the three practice trials.

\section{Behavioural analysis}

Self-endorsement was calculated separately for the pleasant ( $n$ $=30)$ and unpleasant $(n=30)$ words as the percentage of words the participant endorsed as self-descriptive. The distribution of percentage pleasant and unpleasant words endorsed by the participants was nonnormal (Kolmogorov-Smirnov test, $p<.001)$. We therefore used nonparametric tests to assess group differences. Wilcoxon signed-rank test was used to assess if there was a difference between percentage pleasant and unpleasant endorsement for each group. Mann-WhitneyWilcoxon rank-sum test was used to assess if there was a difference in percentage endorsed pleasant and unpleasant words between the two groups.

\section{EEG data acquisition}

Continuous EEG data was acquired at a sampling rate of $1000 \mathrm{~Hz}$ using a 32-channel ActiChamp (Brain Products, Germany) while participants completed the SRET. The ActiChamp system uses active electrodes that improve the 
signal-to-noise ratio at each electrode site. Each channel was ensured to have an impedance below $16 \mathrm{k} \Omega$ before beginning the experiment. The Presentation ${ }^{\circledR}$ software was synchronized to the EEG system by sending TTL pulse triggers through an LPT (parallel) port from the computer used to present stimuli to the data collection computer at the time of each word's onset.

\section{EEG analysis}

EEG analysis was conducted using functions provided in EEGLAB (Delorme \& Makeig, 2004) and custom MATLAB code. Data were first downsampled to $250 \mathrm{~Hz}$, band-pass filtered from 0.05 to $30 \mathrm{~Hz}$ using the functions provided in EEGLAB, and then rereferenced (off-line) to the average of TP9 and TP10 (i.e., average mastoid reference).

We used independent component analysis (ICA) implemented via EEGLAB (Delorme \& Makeig, 2004) to remove ocular and muscle artefacts (Delorme, Sejnowski, \& Makeig, 2007). The components were rejected manually by inspecting them for typical signatures of eye blinks, horizontal eye movements, muscular artifacts (at lateral peripheral channels), and bad channels from each subjects' data set (Chaumon, Bishop, $\&$ Busch, 2015; Jung et al., 2000). All components were removed by the same individual (the first author). On average, we removed 10 components per participant. Following component removal, trials with artefacts were identified automatically (voltage exceeding $\pm 100 \mu \mathrm{V}$ within a 200 -ms window) and were excluded from further analysis. In addition, we visually inspected the remaining trials to detect the presence of other artefacts. Overall, only five such trials were excluded from analysis across all participants.

Event-related potentials To compute event-related potentials (ERPs) we performed baseline subtraction of the mean EEG response within a $250-\mathrm{ms}$ window preceding stimulus onset for each trial and then averaged all included trials between 250 and 1,300 ms around the stimulus onset, separately for pleasant and unpleasant words, within each participant. To aid visualization of ERPs, in Fig. 2 we additionally smoothed the data with a $52 \mathrm{~ms}$ boxcar window (statistically the smoothing had little impact on our results). P200 was quantified by averaging the ERP between 150 and $250 \mathrm{~ms}$ from trial onset (Crowley \& Colrain, 2004), while the early-LPPs and lateLPPs were averaged between 300 and $500 \mathrm{~ms}$ and 800 and $1,000 \mathrm{~ms}$ from stimulus onset, respectively (Auerbach et al., 2015; Keil et al., 2002; Speed et al., 2016). The three ERP components are typically observed over medial frontalcentral-parietal locations. We therefore evaluated them by averaging over CP1, CP2, Cz, FC1, FC2 (Crowley \& Colrain, 2004; Cuthbert, Schupp, Bradley, Birbaumer, \& Lang, 2000; Foti et al., 2009; Hajcak et al., 2009; Herbert, Pauli, et al., 2011b; Schupp et al., 2000; Speed et al., 2016).
Time-frequency analysis As with the ERPs, we first averaged each trial's time series over the channels CP1, CP2, Cz, FC1, $\mathrm{FC} 2$, and then performed time-frequency decomposition on it using MATLAB's spectrogram function, which calculates the short-term Fourier transform of the signal. The time-frequency decomposition was performed starting at stimulus onset to $1,300 \mathrm{~ms}$ in the frequency range $0.05-30 \mathrm{~Hz}$, using a hamming window of $372 \mathrm{~ms}$ with a 364 -ms overlap between consecutive time samples. We calculated the difference of the time-frequency decomposed signal between pleasant and unpleasant words for each group, and then the difference of that difference between the two groups. To obtain time-frequency regions that were reliably different within and between groups, we evaluated 5,000 random permutations of the differences as our null hypothesis, and then used maximum pixel-based thresholding at $\quad=0.05$ (Cohen, 2014).

\section{Analysis of association between behavioural and brain response}

To evaluate the contribution of self-endorsements and LPP in differentiating between the two groups, we performed a binomial logistic regression using the MATLAB function glmfit. We also performed cross-validation using a four-fold classifier (10,000 shuffles) to determine the accuracy of the logistic regression model in differentiating between the two groups.

To investigate the relationship between behavioural and neural response, we used mixed models as implemented in $\mathrm{R}$ (Bates, Mächler, Bolker, \& Walker, 2014; R Core Team, 2013). Mixed models can account for both random and fixed effects while allowing a continuous dependent variable to be used as an "independent" mediator variable for another dependent variable. We modeled group, valence, and LPP amplitude as fixed effects along with a random intercept for each subject to predict behavioural self-endorsements. As our dependent variable was a positive definite value (self-endorsement percentage), we used generalized linear mixed models with the family parameter set to binomial and weight parameter set to the number of trials (30 per valence condition). We ran this model through a Type II analysis of variance, which uses Wald $X^{2}$ tests for obtaining statistical significance on the fixed effects. To get the model fits and trending curves, we used the plot model function available in the sjPlot R package, which uses the ggpredict function of the ggeffects $\mathrm{R}$ package to obtain predicted values of regression models (Lüdecke, 2018a, 2018b).

\section{Results}

\section{Behavioural responses}

Figure 1 shows the percentage of pleasant and unpleasant words endorsed as self-referential. As the self-endorsement 


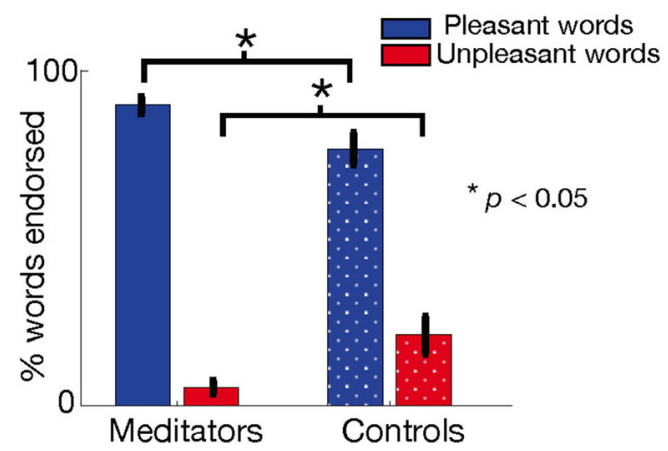

Fig. 1 Percentage of self-endorsed pleasant (black) and unpleasant (grey) adjectives for the two groups, long-term meditators, and controls. Error bars show standard errors of the means. (Colour figure online)

percentage data was nonnormal, we performed nonparametric tests to assess statistical significance (see Method section). Both long-term meditators (Mann-Whitney-Wilcoxon signed-rank test $=91 ; p<.001$, two-tailed) and controls (Mann-WhitneyWilcoxon signed-rank test $=102 ; p<.001$, two-tailed) selfendorsed pleasant adjectives significantly more than unpleasant adjectives. The long-term meditators self-endorsed significantly fewer unpleasant adjectives (Wilcoxon rank-sum test $=142 ; p=$ .027 , two-tailed) and significantly more pleasant adjectives compared with the control group (Wilcoxon rank-sum test $=231 ; p=$ .049 , two-tailed).

As an exploratory analysis, we compared each of the 60 words between the two groups. Supplementary Fig. S1 shows the proportion of individuals that self-endorsed each word in the two groups. To compare each word, we ranked each endorsed word by an individual as 1 and nonendorsed word as 0 . We used a two-tailed Wilcoxon rank-sum test to obtain all words that were self-endorsed statistically differently by the groups at $p<.05$. Compared with the control group, significantly more meditators self-endorsed the words satisfied, radiant, dignified, outstanding, and smooth, and significantly fewer meditators self-endorsed the words rigid, depressed, rejected, sad, and sinful.

\section{Evoked response potentials}

Figure 2a shows the ERPs for pleasant and unpleasant valenced adjectives for the long-term meditator (solid lines) and control (dashed lines) groups. For the P200 (Fig. 2b; left shaded region in Fig. 2a), a 2 (group: meditators, controls) $\times 2$ (valence: pleasant, unpleasant) mixed ANOVA yielded no significant interaction, $F(1,26)=2.33, p=.14$, main effects of group, $F(1,26)=$ $0.0001, p=.99$, or valence, $F(1,26)=0.73, p=0.40$.

For the early-LPP (Fig. 2c; middle shaded region in Fig. 2a), a 2 (group: meditators, controls) $\times 2$ (valence: pleasant, unpleasant) mixed ANOVA yielded a significant interaction between group and valence, $F(1,26)=6.39, p=.018, \eta_{\mathrm{p}}{ }^{2}=$ 0.20 . Neither the main effect of valence, $F(1,26)=2.35, p=$ .14 , nor group, $F(1,26)=1.13, p=.30$, was significant. Post hoc analyses on the early-LPP revealed that the control group had significantly greater response for the unpleasant compared with pleasant words, $t(14)=-3.12, p=.007$, while the meditator group did not, $t(12)=0.65, p=.53$. There was a trend for a lower LPP in response to pleasant words in the control compared with the meditator group, $t(26)=1.97, p=.058$, but no difference between groups for unpleasant words, $t(26)$ $=0.09, p=.93$.

For the late-LPP (Fig. 2d; right shaded region in Fig. 2a), there was no interaction effect (Fig. 2d), $F(1,26)=1.82, p=$ 0.19 , and no main effects of group, $F(1,26)=0.56, p=.46$, and valence, $F(1,26)=1.63, p=.21$.

Figure 3a shows the topography of the Group $\times$ Valence interaction effect plotting the difference between pleasant and unpleasant word evoked early-LPPs with meditators minus controls. As the interaction effect was not significant at $\alpha=$ 0.05 after false-discovery-rate (FDR) correction for multiple comparisons, we mark channels where the interaction effect survived a more lenient FDR-corrected threshold of $p<.10$. The effect was observed across bilateral and medial frontal channels. Post hoc topographies showed that the control participants responded more to unpleasant than to pleasant adjectives over medial and bilateral frontal channels (see Fig. 3c). When doing the same comparison in long-term meditators, we observed that pleasant adjectives evoked a greater early-LPP than unpleasant ones over lateral-frontal and occipital channels, though none of the channels survived an FDR-corrected $p<.10$ (see Fig. 3b).

\section{Association between behavioural and ERP responses}

As both behavioural self-endorsements and early-LPP were different between groups, we tested if the two effects differentiated groups independently. We performed a binomial logistic regression to predict the factor group with two predictors: difference between pleasant and unpleasant self-endorsements, and the difference between pleasant and unpleasant early-LPP, both of which were reduced in controls. We found that LPP $(t=-2.39$; $p=.025)$ and self-endorsements $(t=-2.47 ; p=0.021)$ both predicted group significantly, suggesting that brain and behaviour independently differentiated the groups. A cross-validation procedure on the logistic regression analysis using both LPP and self-endorsements to predict each participant's group yielded a classifier performance of $64.2 \%$.

We then performed further exploratory analyses to investigate a potential relationship between the behavioural selfendorsements and the early-LPP response using generalized linear mixed models; the two levels of valence (pleasant and unpleasant) were included in the model along with the group factor (see Method section). We observed a significant threeway interaction of group, valence, and early-LPP amplitudes (see Fig. 4), $\boldsymbol{X}^{2}(1)=30.10, p<.001$. Visual inspection revealed that this interaction was due to the two groups having 


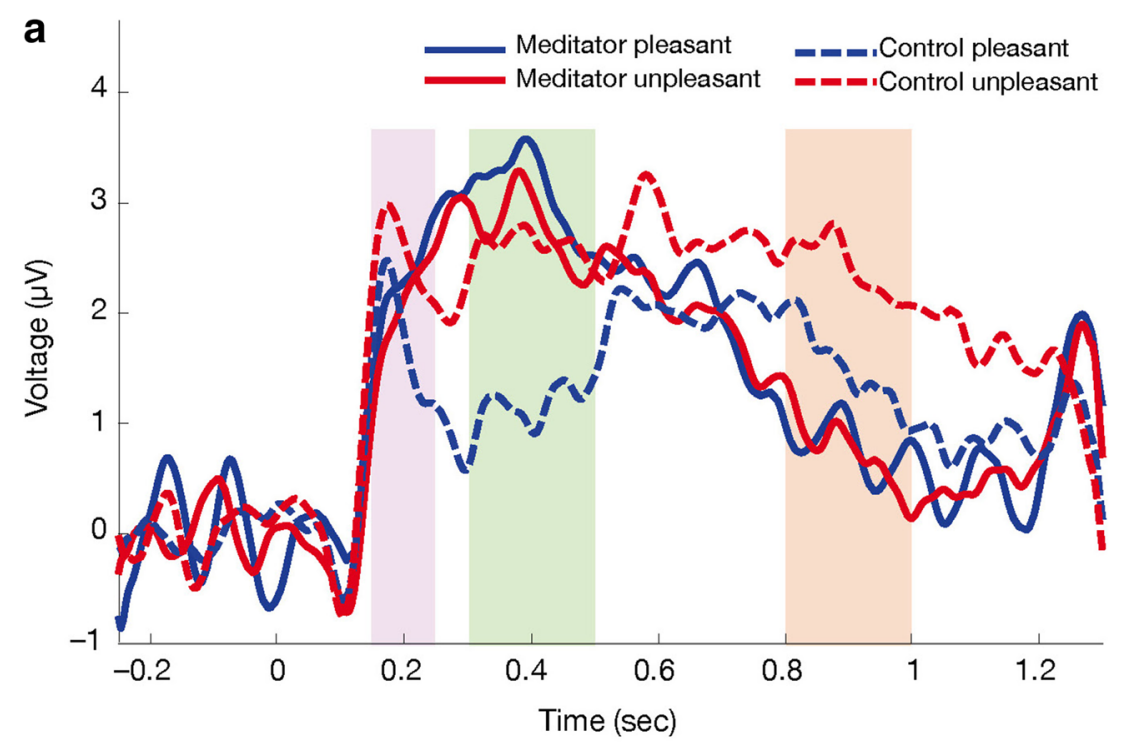

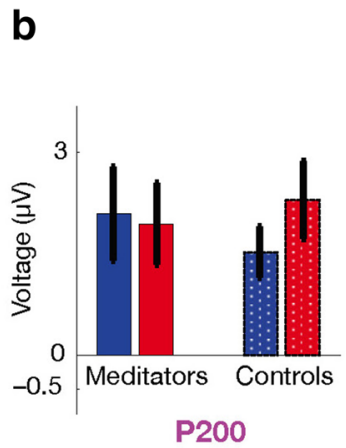

Fig. 2 a ERPs for pleasant (black lines) and unpleasant (grey lines) words presented during the SRET at medial frontal-central channels for longterm meditators (solid lines) and controls (dashed lines). b P200 amplitudes within the leftmost shaded region in a (pleasant and unpleasant

a different relationship between early-LPP and selfendorsements for the two valence conditions. This was confirmed using a post hoc generalized linear mixed model with two factors, valence and early-LPP amplitude, separately for the meditator and control groups. The meditator group showed a significant two-way interaction between valence and early-LPP amplitude in predicting self-endorsements where higher LPPs were associated with increasing pleasant self-endorsements and decreasing unpleasant selfendorsements (see Table 1), $\boldsymbol{X}^{2}(1)=16.81, p<.001$. For the control group, on the other hand, increased LPPs were associated with decreasing pleasant self-endorsements and increasing unpleasant self-endorsements, $\boldsymbol{X}^{2}(1)=36.21, p<$ .001 .

\section{Time-frequency decomposition}

We performed exploratory time-frequency analysis on our data, testing for differences in valence within the two groups, and differences between the groups in the difference of pleasant and unpleasant valence (analogous to the significant mixed-ANOVA interaction effect described above). Figure $5 \mathrm{a}-\mathrm{b}$ show the difference in the time-frequency decomposed signal between pleasant and unpleasant words for the two groups. In the control group (Fig. 5a), we found multiple time-frequency clusters where unpleasant words evoked significantly $(p<.05)$ higher power than the unpleasant words. The biggest of these clusters was in the delta frequency range $(<3 \mathrm{~Hz})$ between 200 and $600 \mathrm{~ms}$ following stimulus onset, corresponding to P200 and early-LPP portions of the ERP. There were also clusters in the theta $(3-6 \mathrm{~Hz})$, alpha $(7.5-10 \mathrm{~Hz})$, beta $(20-22 \mathrm{~Hz})$, and lower gamma (26-30 $\mathrm{Hz}$ ) frequencies around $750-1,000 \mathrm{~ms}$ following stimulus onset corresponding to a late-LPP. In the meditator group (Fig. $5 b)$, there was a significant cluster of pleasant $<$ unpleasant around 750-900 ms following stimulus onset in the lower gamma band $(25-30 \mathrm{~Hz})$ similar to the control group. When taking the difference between the meditator and control group 
a

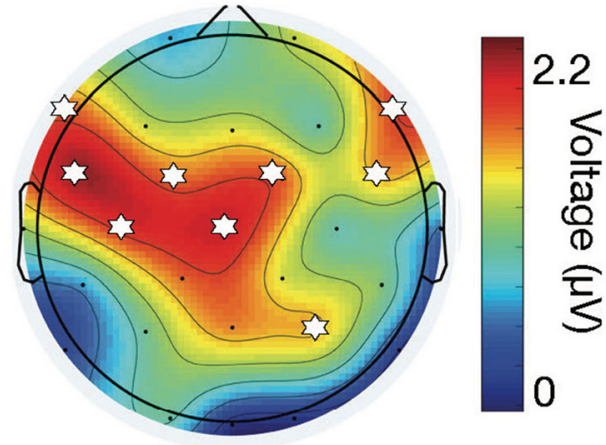

b

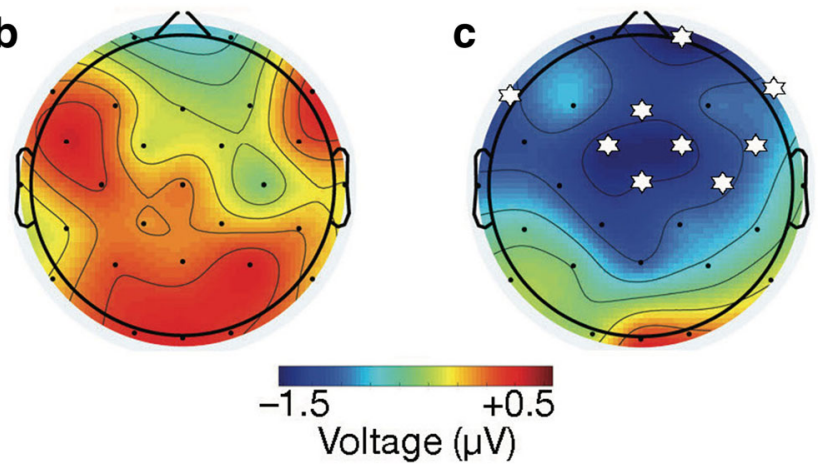

Fig. 3 Topography of the (a) early-LPP interaction effect, and the difference between pleasant and unpleasant words in the (b) meditator, and (c) control groups (stars indicate channels with $p<.10$, FDR corrected). (Colour figure online)

of the difference value between pleasant and unpleasant valence, we found two significant clusters (Fig. $5 \mathrm{c}$ ): one occurring late (900-1,000 ms following stimulus onset) in the theta frequency band $(4-6 \mathrm{~Hz})$, where the difference of pleasant minus unpleasant adjectives was greater in meditators compared with controls, and another occurring early (240-300 ms
Table 1 Three-way and two-way interactions and main effects in the mixed-effects GLM

\begin{tabular}{lll}
\hline Effect & $\chi^{2}(1)$ & $p$ value \\
\hline Three-factor mixed GLM $($ group valence, $L P P)$ & \\
group $\times$ Valence $\times$ LPP & 30.10 & $<10^{-7}$ \\
Group $\times$ Valence & 31.02 & $<10^{-7}$ \\
Valence $\times$ LPP & 7.86 & $<0.01$ \\
Group $\times$ LPP & 0.01 & 0.91 \\
Group & 2.64 & 0.10 \\
Valence & 413.88 & $<10^{-15}$ \\
LPP & 1.85 & 0.17 \\
Two-factor mixed GLM (valence, LPP) in meditators & \\
Valence $\times$ LPP & 12.64 & 0.0004 \\
Valence & 224.09 & $<10^{-15}$ \\
LPP & 0.04 & 0.84 \\
Two-factor mixed GLM (valence, LPP) in controls & \\
Valence $\times$ LPP & 22.10 & $<10^{-5}$ \\
Valence & 209.64 & $<10^{-15}$ \\
LPP & 2.02 & 0.15 \\
\hline
\end{tabular}

following stimulus onset) in the lower beta frequency range $(14-16 \mathrm{~Hz})$ where the same difference was greater in the control group compared with the meditators.

\section{Discussion}

Our goal was to investigate the behavioural and brain correlates of affective self-referential processing in long-term meditators compared with age-matched meditation-naïve controls.

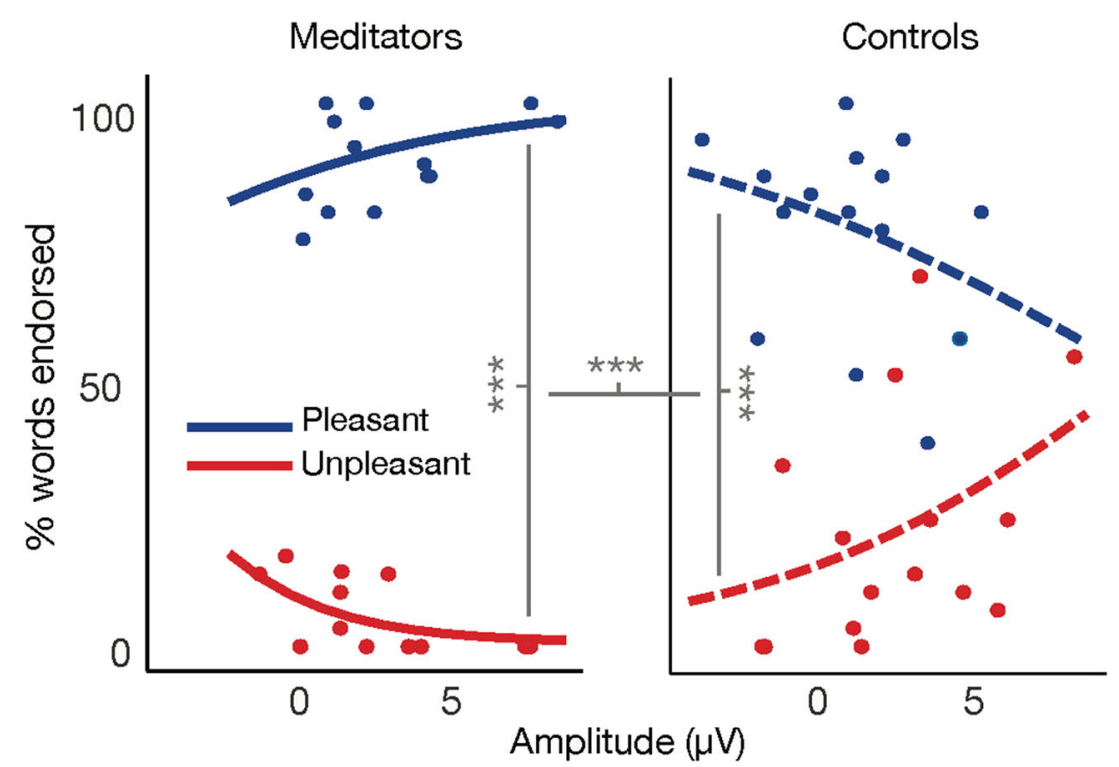

Fig. 4 Fit to a generalized linear mixed model showing the relationship between self-endorsement for pleasant (black) and unpleasant (grey) adjectives, and early-LPP for long-term meditators (solid lines) and controls (dashed lines). Dots indicate individual participants. $* * * p<.001$. (Colour figure online) 

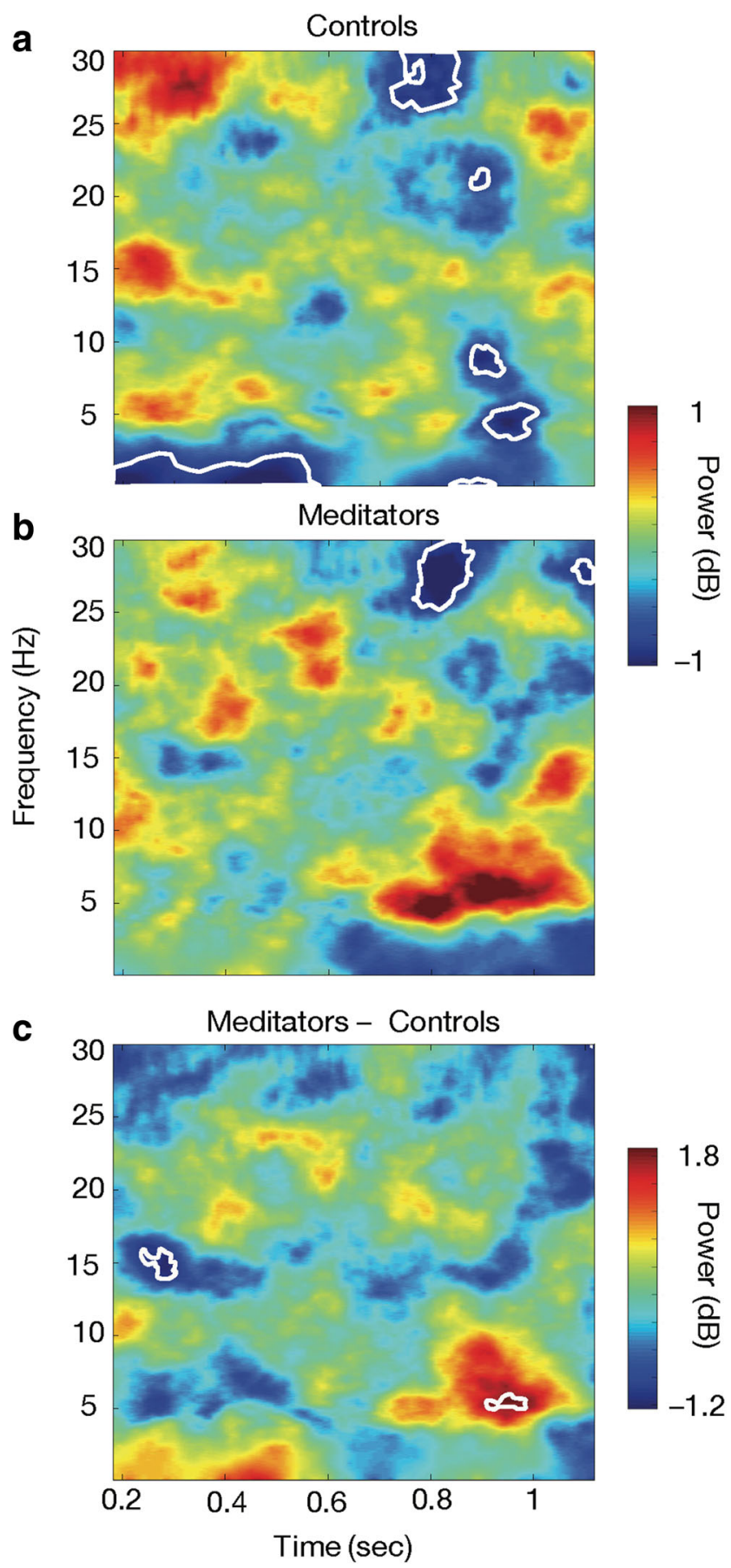

Fig. 5 Time-frequency plots of (a) the difference in power between pleasant and unpleasant words in controls, (b) the difference between pleasant and unpleasant words in meditators, $(\mathbf{c})$ the difference between $\mathbf{a}$ and $\mathbf{b}$. Time on the axis is from the onset of the words. The outlines encompass significant clusters $(p<.05)$. (Colour figure online)

We found that (1) long-term meditators self-endorsed fewer unpleasant and more pleasant adjectives compared with the control group; (2) meditators and controls differed in their early-LPP response, with controls responding to fewer pleasant than unpleasant words, while meditators were not characterized by this difference; and (3) meditators had an association between early-LPP and self-endorsement of more pleasant and fewer unpleasant adjectives, while controls showed the opposite pattern.

Previous studies have shown that healthy individuals tend to self-endorse more pleasant than unpleasant words (e.g., Auerbach et al., 2015; Derry \& Kuiper, 1981; Goldin et al., 2009; Kuiper \& Derry, 1982). This is in contrast with individuals suffering from depression, anxiety, and borderline personality disorder who tend to self-endorse more unpleasant than pleasant words (Derry \& Kuiper, 1981; Dozois \& Dobson, 2001; Kuiper \& Derry, 1982; Thurston, Goldin, Heimberg, \& Gross, 2017). In the current study, long-term meditators endorsed significantly more pleasant and significantly fewer unpleasant words than the controls, reflecting more positive and adaptive self-views. Such behavioural differences in self-views of our group of meditators, when considering their contemplative tradition of meditation training, could be an outcome of several underlying factors, such as the following: (1) A more self-contented attitude towards life (for example, while endorsing words such as satisfied, confident, grateful, secure, and not endorsing words like helpless, displeased, insecure). This is codified most prominently in Ananda Marga practices (which our long-term meditator group engaged in) through the self-directed ethical principle (or niyama) of santosha, meaning satisfaction or contentment (Anandamurti, 1981). (2) Specific pleasant qualities that they experience in their practice (for example, a greater sense of being patient, joyful, relaxed, and reduced sense of being anxious, depressed, unhappy, angry). The meditator group engaged practices that are said to induce experiences of joy and bliss (ananda). While attachment to such experiences is considered a hindrance on the path, their experience leading to a continued engagement with practice is generally encouraged in Yogic contemplative traditions (Bharati, 2001). 3) Qualities that may be considered a combination of experience through practice as well as part of the socially embedded values that the practitioners were conforming to while responding (for example, in endorsing words like moral, wise, radiant, dignified, and not endorsing sinful, helpless, useless, rejected).

Visual inspection revealed a difference in ERPs for longterm meditators compared with controls around $200 \mathrm{~ms}$ following stimulus onset over medial-central electrodes reflecting sustained differences in cognitive-affective processing (Fig. 2a). While the meditators' response did not seem to differ between pleasant and unpleasant words, nonmeditators were characterized by a reduced LPP to pleasant compared with unpleasant words.

For the early-LPP component, the difference between pleasant and unpleasant words between groups was statistically significant widely across medial and bilateral frontal channels. Previous MRI-based studies of longitudinal contemplative training have found similar neural loci corresponding to self-referential processing (Goldin et al., 2009; Lumma, Valk, 
Böckler, Vrtička, \& Singer, 2018). Post hoc topographies revealed that the effect was primarily driven by the control group's reduced response to pleasant compared with unpleasant words over medial and bilateral frontal-central electrode sites, suggesting lower pleasant self-view processing in the control group (Northoff \& Bermpohl, 2004).

The opposite pattern of early-LPP for pleasant versus unpleasant words between groups is akin to findings between healthy versus clinical populations using the SRET (Auerbach et al., 2015; Auerbach et al., 2016; Shestyuk \& Deldin, 2010; Speed et al., 2016). In these past studies, individuals diagnosed with or prone to depression and borderline personality disorder exhibited a smaller difference between pleasant and unpleasant LPPs compared with healthy populations - that is, the value of pleasant-word-evoked minus unpleasant-word-evoked LPP was smaller in the clinical group. In this context, our results suggest that meditators have a "healthier" neural response than the healthy control group, as the latter also had a smaller pleasant minus unpleasant value of the LPP than the former did.

While the control group self-endorsed more pleasant than unpleasant words, their early-LPP response was in the opposite direction, reflecting a "self-related negativity bias". Past studies investigating self-related affect in healthy groups have been ambiguous with regard to whether there should be a positivity (towards pleasant words) and negativity (towards unpleasant words) bias in the LPP response, with some studies showing higher LPPs for pleasant compared with unpleasant self-referential words (e.g., Auerbach et al., 2015; Herbert, Herbert, et al., 2011a; Shestyuk \& Deldin, 2010; Watson et al., 2007), while others show a self-related negativity bias of the kind we observed (e.g., Bernat, Bunce, \& Shevrin, 2001; Fields \& Kuperberg, 2012; Herbert, Pauli, et al., 2011b; Zhou et al., 2017). This negativity bias might also be related to the age the control group (mean age $=54$ years). Only one previous study has been conducted on a middle-to-old age group (mean age $=43$ years), which also showed a negativity bias (Zhou et al., 2017).

In contrast to the control group, the meditators did not respond differently to pleasant and unpleasant words. While being aware of the caveats in interpreting statistical null effects, we briefly discuss this due to its meaningfulness in contemplative research. Ananda Marga practitioners aim to attain a state of pure phenomenal awareness or a "witnessing self" beyond mental perturbations through daily long-term practice. In the attainment of this long-term goal, as one's practice advances, they are said to gradually let go of the idea of an egocentric selfidentity (Anandamurti, 1998). Self-related affect is evaluated from a more distanced (e.g., a third person) perspective that helps cultivate an equanimous disposition (e.g., Anandamurti, 1994). Thus, we would expect a more similar response to pleasant and unpleasant self-views, of the kind we observed in our study.

Our exploratory time-frequency analysis investigated spectral measures in the EEG. Consistent with the overall greater ERP amplitudes to unpleasant compared with pleasant adjectives for the control group, we found multiple significant timefrequency clusters with higher power for unpleasant compared with pleasant adjectives. Some of these differences likely corresponded to the P200 and early-LPP (at low frequencies), and late-LPP (spanning a larger spectrum of frequencies). Greater power for unpleasant versus pleasant adjectives was also observed in the mediators at high frequencies similar to control group, suggesting that such a response might reflect generally increased processing of unpleasant compared with pleasant valence, regardless of meditation training. Unlike the ERPs, we did not find a significant effect between groups between pleasant and unpleasant valence during the time range of the early-LPP (i.e., corresponding to the interaction effect). We suspect this could be due to the difference in valence between the groups becoming "diffused" over a larger range of time and frequencies, and therefore not reaching statistical reliability. The time-frequency decomposition showed a similar difference between the groups in the time range of the late-LPP, which was not observed in the ERP probably due to it not being in the delta band. The ERP and time-frequency analysis therefore seem to offer complementary information and recommended to be included in future research. Overall, our time-frequency analysis indicates that the previously reported differences in early-LPPS and late-LPPs for affective processing (e.g., Auerbach et al., 2016; Dennis \& Hajcak, 2009; Foti et al., 2009) might also involve different frequency signatures. The early-LPP might differentiate valence primarily at low frequencies $(<3 \mathrm{~Hz})$. The late-LPP might span a larger spectrum of frequencies, of which the theta band is more amenable to manipulation (for example, via meditation training), while other frequencies are not.

In addition to group differences in behaviour (selfendorsement) and brain (early-LPP), our exploratory results also show that the two groups markedly differ in the relationship between brain and behaviour. While in the meditator group, increasing LPP response was associated with higher pleasant and lower unpleasant self-endorsements, the control group showed the opposite pattern. This indicates that the LPP could be reflecting two different subprocesses, one where the neural mechanism underlying higher LPP is maladaptive and another where it is adaptive. The presence of two different processes could also explain the ambiguity of positivity and negativity bias in LPP across different studies of self-related affect (Fields \& Kuperberg, 2012; Herbert, Herbert, et al., 2011a; Herbert, Pauli, et al., 2011b; Watson et al., 2007). Future studies can be designed to disentangle the presence of these complementary dual processes. 
Past clinical research has shown that maladaptive selfviews are a hallmark of clinical disorders such as depression and anxiety (Beck, 1967; Blackburn \& Eunson, 1989; Blaney, 1986; Williams, Healy, Teasdale, White, \& Paykel, 1990). Processing of unpleasant views of the self has been shown to be heightened using SRET during such disorders (Derry \& Kuiper, 1981; Dozois \& Dobson, 2001; Kuiper \& Derry, 1982; Lemogne et al., 2010; Thurston et al., 2017). Contemplative therapeutic programs like mindfulness-based stress reduction (MBSR) and mindfulness-based cognitive therapy have been shown to be effective alternatives to psychotropic medication for treating symptoms of depression and anxiety (Hofmann et al., 2010) and for the prevention of relapse in depression (Kuyken et al., 2015; Segal et al., 2010). Our findings indicate that the improvement of such disorders with mindfulness and meditation could occur by shifting one's focus to more adaptive self-views (Goldin et al., 2009; Thurston et al., 2017).

One limitation of our study is that even though the two groups were matched for demographic factors such as age and education, the differences between them may not have been due to meditation training, but rather to a self-selection bias of the meditator group, or other types of lifestyle choices made by the groups throughout their lives (e.g., many of the participants of the meditator group lived a monastic lifestyle; all of them followed a vegetarian diet during the course of their practice). This is a shortcoming of any cross-sectional study on long-term contemplative training. Any interpretation of the present results, therefore, should be made with caution and in relation to the limitations of a cross-sectional design. However, considering that contemplative practices and the lifestyle choices undertaken by the meditator group used in our study were developed within a context of transforming one's self-concept from an egocentric to a more transpersonal one, we can argue that the contemplative training (of which the lifestyle is an integral part) likely influenced the kinds of between-group differences observed here. Future studies could use first-person investigation to supplement thirdperson methods of the kinds used here to better understand the role of self-selectivity bias, mental training, and lifestyle with somewhat greater clarity.

Another limitation is that while we observe neural differences in processing of pleasant and unpleasant self-views between groups, potentially reflecting different strategies and underlying processes for evaluating affective self-views, we did not (1) use a high-density EEG to give us more precise cortical sources for ascertaining anatomical differences and (2) conduct interviews to investigate if participants were aware of the strategies they were using to evaluate differences between valence.

To summarize, long-term meditators have self-reference processing styles characterized by behavioural and brain responses that are less maladaptive than controls. Such changes might be how long-term meditation training supports a more flexible and healthy relationship to one's self, and may be a critical factor mediating improvement in mood disorders following contemplative-training-based therapy programs.

Open practices statement The data for figures and statistical analyses scripts are available at https://osf.io/xq8vw/. The experiment was not preregistered.

Funding This work was funded by a Varela Award to S.K. [2015-VarelaKatyal,Sucharit] and P.G.'s start-up funds.

\section{References}

Albahari, M. (2006). Analytical Buddhism: The two-tiered illusion of self. Basingstoke, England: Palgrave Macmillan.

Anandamurti, S. S. (1981). A guide to human conduct. Kolkata, India: Ananda Marga Publications.

Anandamurti, S. S. (1994). Jaeva Dharma and Bhagavata Dharma. In Subhasita Samgraha (Part 21). Kolkata, India: Ananda Marga Publications.

Anandamurti, S. S. (1998). Ananda Marga elementary philosophy. Kolkata, India: Ananda Marga Publications.

Auerbach, R. P., Stanton, C. H., Proudfit, G. H., \& Pizzagalli, D. A. (2015). Self-referential processing in depressed adolescents: A high-density ERP study. Journal of Abnormal Psychology, 124(2), 233-245. doi:https://doi.org/10.1037/abn0000023

Auerbach, R. P., Tarlow, N., Bondy, E., Stewart, J. G., Aguirre, B., Kaplan, C., ... Pizzagalli, D. A. (2016). Electrocortical reactivity during self-referential processing in female youth with borderline personality disorder. Biological Psychiatry: Cognitive Neuroscience and Neuroimaging, 1(4), 335-344. doi:https://doi. org/10.1016/j.bpsc.2016.04.004

Austin, J. H. (2011). Selfless insight: Zen and the meditative transformations of consciousness. Cambridge, MA: MIT Press.

Banks, S. J., Eddy, K. T., Angstadt, M., Nathan, P. J., \& Phan, K. L. (2007). Amygdala-frontal connectivity during emotion regulation. Social Cognitive and Affective Neuroscience, 2(4), 303-312. doi: https://doi.org/10.1093/scan/nsm029

Bates, D., Mächler, M., Bolker, B., \& Walker, S. (2014). Fitting linear mixed-effects models using lme4. ArXiv:1406.5823 [Stat]. Retrieved from http://arxiv.org/abs/1406.5823

Beck, A. T. (1967). Depression: Clinical, experimental, and theoretical aspects. Philadelphia: University of Pennsylvania Press.

Berkovich-Ohana, A., Glicksohn, J., \& Goldstein, A. (2012). Mindfulness-induced changes in gamma band activityImplications for the default mode network, self-reference and attention. Clinical Neurophysiology, 123(4), 700-710. doi:https://doi. org/10.1016/j.clinph.2011.07.048

Bernat, E., Bunce, S., \& Shevrin, H. (2001). Event-related brain potentials differentiate positive and negative mood adjectives during both supraliminal and subliminal visual processing. International Journal of Psychophysiology, 42(1), 11-34. doi:https://doi.org/10. 1016/S0167-8760(01)00133-7

Bharati, S. V. (2001). Yoga Sutras of Patanjali: With the exposition of Vyasa. New Delhi, India: Motilal Banarsidass Publishers.

Bishop, S. R., Lau, M., Shapiro, S., Carlson, L., Anderson, N. D., Carmody, J., ... Devins, G. (2004). Mindfulness: A proposed operational definition. Clinical Psychology: Science and Practice, 11(3), 230-241. doi:https://doi.org/10.1093/clipsy.bph077

Blackburn, I. M., \& Eunson, K. M. (1989). A content analysis of thoughts and emotions elicited from depressed patients during cognitive therapy. Psychology and Psychotherapy: Theory, Research and 
Practice, 62(1), 23-33. doi:https://doi.org/10.1111/j.2044-8341. 1989.tb02807.x

Blaney, P. H. (1986). Affect and memory: A review. Psychological Bulletin, 99(2), 229. doi:https://doi.org/10.1037/0033-2909.99.2. 229

Bradley, M. M., \& Lang, P. J. (1999). Affective norms for English words (ANEW): Instruction manual and affective ratings (Technical Report C-1). Gainesville: The Center for Research in Psychophysiology, University of Florida.

Cahn, B. R., Delorme, A., \& Polich, J. (2013). Event-related delta, theta, alpha and gamma correlates to auditory oddball processing during Vipassana meditation. Social Cognitive and Affective Neuroscience, 8(1), 100-111. doi:https://doi.org/10.1093/scan/nss060

Chaumon, M., Bishop, D. V., \& Busch, N. A. (2015). A practical guide to the selection of independent components of the electroencephalogram for artifact correction. Journal of Neuroscience Methods, 250, 47-63. doi:https://doi.org/10.1016/j.jneumeth.2015.02.025

Chiesa, A., Calati, R., \& Serretti, A. (2011). Does mindfulness training improve cognitive abilities? A systematic review of neuropsychological findings. Clinical Psychology Review, 31(3), 449-464. doi: https://doi.org/10.1016/j.cpr.2010.11.003

Cohen, M. X. (2014). Analyzing neural time series data: Theory and practice. Cambridge, MA: MIT Press.

Crowley, K. E., \& Colrain, I. M. (2004). A review of the evidence for P2 being an independent component process: Age, sleep and modality. Clinical Neurophysiology, 115(4), 732-744. doi:https://doi.org/10. 1016/j.clinph.2003.11.021

Cuthbert, B. N., Schupp, H. T., Bradley, M. M., Birbaumer, N., \& Lang, P. J. (2000). Brain potentials in affective picture processing: Covariation with autonomic arousal and affective report. Biological Psychology, 52(2), 95-111. doi:https://doi.org/10.1016/ s0301-0511(99)00044-7

Dahl, C. J., Lutz, A., \& Davidson, R. J. (2015). Reconstructing and deconstructing the self: Cognitive mechanisms in meditation practice. Trends in Cognitive Sciences, 19(9), 515-523. doi:https://doi. org/10.1016/j.tics.2015.07.001

Delorme, A., \& Makeig, S. (2004). EEGLAB: An open source toolbox for analysis of single-trial EEG dynamics including independent component analysis. Journal of Neuroscience Methods, 134(1), 921. doi:https://doi.org/10.1016/j.jneumeth.2003.10.009

Delorme, A., Sejnowski, T., \& Makeig, S. (2007). Enhanced detection of artifacts in EEG data using higher-order statistics and independent component analysis. NeuroImage, 34(4), 1443-1449. doi:https:// doi.org/10.1016/j.neuroimage.2006.11.004

Dennis, T. A., \& Hajcak, G. (2009). The late positive potential: A neurophysiological marker for emotion regulation in children. Journal of Child Psychology and Psychiatry, 50(11), 1373-1383. doi:https:// doi.org/10.1111/j.1469-7610.2009.02168.x

Derry, P. A., \& Kuiper, N. A. (1981). Schematic processing and selfreference in clinical depression. Journal of Abnormal Psychology, 90(4), 286-297. doi:https://doi.org/10.1037//0021-843x.90.4.286

Desbordes, G., Gard, T., Hoge, E. A., Hölzel, B. K., Kerr, C., Lazar, S. W., ... Vago, D. R. (2015). Moving beyond mindfulness: Defining equanimity as an outcome measure in meditation and contemplative research. Mindfulness, 6(2), 356-372. doi:https://doi.org/10.1007/ s12671-013-0269-8

Dorjee, D. (2016). Defining contemplative science: The metacognitive self-regulatory capacity of the mind, context of meditation practice and modes of existential awareness. Frontiers in Psychology, 7, 1788. doi:https://doi.org/10.3389/fpsyg.2016.01788

Dozois, D. J., \& Dobson, K. S. (2001). Information processing and cognitive organization in unipolar depression: Specificity and comorbidity issues. Journal of Abnormal Psychology, 110(2), 236-246. doi:https://doi.org/10.1037//0021-843x.110.2.236

Farb, N. A. S., Segal, Z. V., Mayberg, H., Bean, J., McKeon, D., Fatima, Z., \& Anderson, A. K. (2007). Attending to the present: Mindfulness meditation reveals distinct neural modes of self-reference. Social Cognitive and Affective Neuroscience, 2(4), 313-322. doi:https:// doi.org/10.1093/scan/nsm030

Fields, E. C., \& Kuperberg, G. R. (2012). It's all about you: An ERP study of emotion and self-relevance in discourse. NeuroImage, 62(1), 562-574. doi:https://doi.org/10.1016/j.neuroimage.2012.05.003

Fischler, I., \& Bradley, M. (2006). Event-related potential studies of language and emotion: Words, phrases, and task effects. Progress in Brain Research, 156, 185-203. doi:https://doi.org/10.1016/S00796123(06)56009-1

Fossati, P., Hevenor, S. J., Graham, S. J., Grady, C., Keightley, M. L., Craik, F., \& Mayberg, H. (2003). In search of the emotional self: An fMRI study using positive and negative emotional words. American Journal of Psychiatry, 160(11), 1938-1945. doi:https://doi.org/10. 1176/appi.ajp.160.11.1938

Foti, D., Hajcak, G., \& Dien, J. (2009). Differentiating neural responses to emotional pictures: Evidence from temporal-spatial PCA. Psychophysiology, 46(3), 521-530. doi:https://doi.org/10.1111/j. 1469-8986.2009.00796.x

Goldin, P., Ramel, W., \& Gross, J. (2009). Mindfulness meditation training and self-referential processing in social anxiety disorder: Behavioral and neural effects. Journal of Cognitive Psychotherapy, 23(3), 242-257. doi:https://doi.org/10.1891/08898391.23.3.242

Gusnard, D. A., Akbudak, E., Shulman, G. L., \& Raichle, M. E. (2001). Medial prefrontal cortex and self-referential mental activity: Relation to a default mode of brain function. Proceedings of the National Academy of Sciences of the United States of America, 98(7), 4259-4264. doi:https://doi.org/10.1073/pnas.071043098

Hajcak, G., Dunning, J. P., \& Foti, D. (2009). Motivated and controlled attention to emotion: Time-course of the late positive potential. Clinical Neurophysiology, 120(3), 505-510. doi:https://doi.org/10. 1016/j.clinph.2008.11.028

Hajcak, G., \& Olvet, D. M. (2008). The persistence of attention to emotion: Brain potentials during and after picture presentation. Emotion, 8(2), 250-255. doi:https://doi.org/10.1037/1528-3542.8.2.250

Herbert, C., Herbert, B. M., Ethofer, T., \& Pauli, P. (2011a). His or mine? The time course of self-other discrimination in emotion processing. Social Neuroscience, 6(3), 277-288. doi:https://doi.org/10.1080/ 17470919.2010.523543

Herbert, C., Junghofer, M., \& Kissler, J. (2008). Event related potentials to emotional adjectives during reading. Psychophysiology, 45(3), 487-498. doi:https://doi.org/10.1111/j.1469-8986.2007.00638.x

Herbert, C., Pauli, P., \& Herbert, B. M. (2011b). Self-reference modulates the processing of emotional stimuli in the absence of explicit selfreferential appraisal instructions. Social Cognitive and Affective Neuroscience, 6(5), 653-661. doi:https://doi.org/10.1093/scan/ nsq082

Hofmann, S. G., Sawyer, A. T., Witt, A. A., \& Oh, D. (2010). The effect of mindfulness-based therapy on anxiety and depression: A metaanalytic review. Journal of Consulting and Clinical Psychology, 78(2), 169-183. doi:https://doi.org/10.1037/a0018555

Holt, D. J., Lynn, S. K., \& Kuperberg, G. R. (2009). Neurophysiological correlates of comprehending emotional meaning in context. Journal of Cognitive Neuroscience, 21(11), 2245-2262. doi:https://doi.org/ 10.1162/jocn.2008.21151

Huang, Y.-X., \& Luo, Y.-J. (2006). Temporal course of emotional negativity bias: An ERP study. Neuroscience Letters, 398(1), 91-96. doi: https://doi.org/10.1016/j.neulet.2005.12.074

Jimenez, S. S., Niles, B. L., \& Park, C. L. (2010). A mindfulness model of affect regulation and depressive symptoms: Positive emotions, mood regulation expectancies, and self-acceptance as regulatory mechanisms. Personality and Individual Differences, 49(6), 645650. doi:https://doi.org/10.1016/j.paid.2010.05.041

Jung, T.-P., Makeig, S., Humphries, C., Lee, T.-W., Mckeown, M. J., Iragui, V., \& Sejnowski, T. J. (2000). Removing 
electroencephalographic artifacts by blind source separation. Psychophysiology, 37(2), 163-178. doi:https://doi.org/10.1111/ 1469-8986.3720163

Keil, A., Bradley, M. M., Hauk, O., Rockstroh, B., Elbert, T., \& Lang, P. J. (2002). Large-scale neural correlates of affective picture processing. Psychophysiology, 39(5), 641-649. doi:https://doi.org/10.1017/ S0048577202394162

Kissler, J., Herbert, C., Peyk, P., \& Junghofer, M. (2007). Buzzwords: Early cortical responses to emotional words during reading. Psychological Science, 18(6), 475-480. doi:https://doi.org/10. 1111/j.1467-9280.2007.01924.x

Knyazev, G. (2013). EEG correlates of self-referential processing. Frontiers in Human Neuroscience, 7. doi:https://doi.org/10.3389/ fnhum.2013.00264

Kuiper, N. A., \& Derry, P. A. (1982). Depressed and nondepressed content self-reference in mild depressives. Journal of Personality, 50(1), 67-80. doi:https://doi.org/10.1111/j.1467-6494.1982.tb00746.x

Kuyken, W., Hayes, R., Barrett, B., Byng, R., Dalgleish, T., Kessler, D., ... Byford, S. (2015). Effectiveness and cost-effectiveness of mindfulness-based cognitive therapy compared with maintenance antidepressant treatment in the prevention of depressive relapse or recurrence (PREVENT): A randomised controlled trial. The Lancet, 386(9988), 63-73. doi:https://doi.org/10.1016/S0140-6736(14) 62222-4

Lemogne, C., Mayberg, H., Bergouignan, L., Volle, E., Delaveau, P., Lehéricy, S., ... Fossati, P. (2010). Self-referential processing and the prefrontal cortex over the course of depression: A pilot study. Journal of Affective Disorders, 124(1), 196-201. doi:https://doi.org/ 10.1016/j.jad.2009.11.003

Lüdecke, D. (2018a). ggeffects: Tidy data frames of marginal effects from regression models. Journal of Open Source Software, 3(26), 772. doi:https://doi.org/10.21105/joss.00772

Lüdecke, D. (2018b). sjPlot: Data visualization for statistics in social science (R Package Version, 2[1]) [Computer software]. Retrieved from https://rdrr.io/cran/sjPlot/

Lumma, A.-L., Valk, S. L., Böckler, A., Vrtička, P., \& Singer, T. (2018). Change in emotional self-concept following socio-cognitive training relates to structural plasticity of the prefrontal cortex. Brain and Behavior, 8(4), e00940. doi:https://doi.org/10.1002/brb3.940

Lutz, A., Jha, A. P., Dunne, J. D., \& Saron, C. D. (2015). Investigating the phenomenological matrix of mindfulness-related practices from a neurocognitive perspective. American Psychologist, 70(7), 632658. doi:https://doi.org/10.1037/a0039585

Mellings, T. M., \& Alden, L. E. (2000). Cognitive processes in social anxiety: The effects of self-focus, rumination and anticipatory processing. Behaviour Research and Therapy, 38(3), 243-257. doi: https://doi.org/10.1016/s0005-7967(99)00040-6

Naumann, E., Bartussek, D., Diedrich, O., \& Laufer, M. E. (1992). Assessing cognitive and affective information processing functions of the brain by means of the late positive complex of the eventrelated potential. Journal of Psychophysiology, 6(4), 285-298.

Northoff, G., \& Bermpohl, F. (2004). Cortical midline structures and the self. Trends in Cognitive Sciences, 8(3), 102-107. doi:https://doi. org/10.1016/j.tics.2004.01.004

Ochsner, K. N., Knierim, K., Ludlow, D. H., Hanelin, J., Ramachandran, T., Glover, G., \& Mackey, S. C. (2004). Reflecting upon feelings: An fMRI study of neural systems supporting the attribution of emotion to self and other. Journal of Cognitive Neuroscience, 16(10), 1746-1772. doi:https://doi.org/10.1162/0898929042947829

Paulmann, S., Bleichner, M., \& Kotz, S. A. E. (2013). Valence, arousal, and task effects in emotional prosody processing. Frontiers in Psychology, 4. doi:https://doi.org/10.3389/fpsyg.2013.00345

R Core Team. (2013). R: A language and environment for statistical computing [Computer software]. Retrieved from https://www.rproject.org/
Ramesh, M. G., Sathian, B., Sinu, E., \& Kiranmai, S. R. (2013). Efficacy of Rajayoga meditation on positive thinking: An index for selfsatisfaction and happiness in life. Journal of Clinical and Diagnostic Research: JCDR, 7(10), 2265. doi:https://doi.org/10. 7860/JCDR/2013/5889.3488

Rogers, T. B., Kuiper, N. A., \& Kirker, W. S. (1977). Self-reference and the encoding of personal information. Journal of Personality and Social Psychology, 35(9), 677-688. doi:https://doi.org/10.1037// 0022-3514.35.9.677

Ruchkin, D. S., Johnson, R., Mahaffey, D., \& Sutton, S. (1988). Toward a functional categorization of slow waves. Psychophysiology, 25(3), 339-353. doi:https://doi.org/10.1111/j.1469-8986.1988.tb01253.x

Schupp, H. T., Cuthbert, B. N., Bradley, M. M., Cacioppo, J. T., Ito, T., \& Lang, P. J. (2000). Affective picture processing: The late positive potential is modulated by motivational relevance. Psychophysiology, 37(2), 257-261. doi:https://doi.org/10.1111/ 1469-8986.3720257

Sedlmeier, P. (2018). Meditation and altered states of consciousness. Journal of Consciousness Studies, 25(11/12), 73-101. Retrieved from https://www.ingentaconnect.com/content/imp/jcs/2018/ 00000025/f0020011/art00005

Sedlmeier, P., \& Srinivas, K. (2016). How do theories of cognition and consciousness in ancient Indian thought systems relate to current Western theorizing and research? Frontiers in Psychology, 7. doi: https://doi.org/10.3389/fpsyg.2016.00343

Segal, Z. V., Bieling, P., Young, T., MacQueen, G., Cooke, R., Martin, L., ... Levitan, R. D. (2010). Antidepressant monotherapy vs sequential pharmacotherapy and mindfulness-based cognitive therapy, or placebo, for relapse prophylaxis in recurrent depression. Archives of General Psychiatry, 67(12), 1256-1264. doi:https://doi.org/10. 1001/archgenpsychiatry.2010.168

Shestyuk, A. Y., \& Deldin, P. J. (2010). Automatic and strategic representation of the self in major depression: Trait and state abnormalities. American Journal of Psychiatry, 167(5), 536-544. doi:https:// doi.org/10.1176/appi.ajp.2009.06091444

Sobolewski, A., Holt, E., Kublik, E., \& Wróbel, A. (2011). Impact of meditation on emotional processing-A visual ERP study. Neuroscience Research, 71(1), 44-48. doi:https://doi.org/10.1016/ j.neures.2011.06.002

Speed, B. C., Nelson, B. D., Auerbach, R. P., Klein, D. N., \& Hajcak, G. (2016). Depression risk and electrocortical reactivity during selfreferential emotional processing in 8- to 14-year-old girls. Journal of Abnormal Psychology, 125(5), 607-619. doi:https://doi.org/10. 1037/abn0000173

Symons, C. S., \& Johnson, B. T. (1997). The self-reference effect in memory: A meta-analysis. Psychological Bulletin, 121(3), 371394. doi:https://doi.org/10.1037/0033-2909.121.3.371

Tang, Y.-Y., Hölzel, B. K., \& Posner, M. I. (2015). The neuroscience of mindfulness meditation. Nature Reviews Neuroscience, 16(4), 213 225. doi:https://doi.org/10.1038/nrn3916

Thomas, S. J., Johnstone, S. J., \& Gonsalvez, C. J. (2007). Event-related potentials during an emotional Stroop task. International Journal of Psychophysiology, 63(3), 221-231. doi:https://doi.org/10.1016/j. ijpsycho.2006.10.002

Thompson, B. L., \& Waltz, J. A. (2008). Mindfulness, self-esteem, and unconditional self-acceptance. Journal of Rational-Emotive \& Cognitive-Behavior Therapy, 26(2), 119-126. doi:https://doi.org/ 10.1007/s10942-007-0059-0

Thompson, E. (2014). Waking, dreaming, being: Self and consciousness in neuroscience, meditation, and philosophy. New York, NY: Columbia University Press.

Thurston, M. D., Goldin, P., Heimberg, R., \& Gross, J. J. (2017). Selfviews in social anxiety disorder: The impact of CBT versus MBSR. Journal of Anxiety Disorders, 47, 83-90. doi:https://doi.org/10. 1016/j.janxdis.2017.01.001 
Vago, D. R., \& Silbersweig, D. A. (2012). Self-awareness, self-regulation, and self-transcendence (S-ART): A framework for understanding the neurobiological mechanisms of mindfulness. Frontiers in Human Neuroscience, 6. doi:https://doi.org/10.3389/fnhum.2012. 00296

Van Ness, P. H. (1999). Yoga as spiritual but not religious: A pragmatic perspective. American Journal of Theology \& Philosophy, 20(1), 15-30. Retrieved from https://www.jstor.org/stable/27944075

Watkins, E. D., \& Teasdale, J. D. (2001). Rumination and overgeneral memory in depression: Effects of self-focus and analytic thinking. Journal of Abnormal Psychology, 110(2), 353-357. doi:https://doi. org/10.1037/0021-843x.110.2.333

Watson, L. A., Dritschel, B., Obonsawin, M. C., \& Jentzsch, I. (2007). Seeing yourself in a positive light: Brain correlates of the selfpositivity bias. Brain Research, 1152, 106-110. doi:https://doi.org/ 10.1016/j.brainres.2007.03.049

Williams, J. M. G., Healy, D., Teasdale, J. D., White, W., \& Paykel, E. S. (1990). Dysfunctional attitudes and vulnerability to persistent depression. Psychological Medicine, 20(2), 375-381. doi:https:// doi.org/10.1017/S0033291700017694

Yoshimura, S., Ueda, K., Suzuki, S., Onoda, K., Okamoto, Y., \& Yamawaki, S. (2009). Self-referential processing of negative stimuli within the ventral anterior cingulate gyrus and right amygdala. Brain and Cognition, 69(1), 218-225. doi:https://doi.org/10.1016/j.bandc. 2008.07.010

Zhou, H., Guo, J., Ma, X., Zhang, M., Liu, L., Feng, L., ... Zhong, N. (2017). Self-reference emerges earlier than emotion during an implicit self-referential emotion processing task: Event-related potential evidence. Frontiers in Human Neuroscience, 11. doi:https://doi. org/10.3389/fnhum.2017.00451

Publisher's note Springer Nature remains neutral with regard to jurisdictional claims in published maps and institutional affiliations. 